\title{
Internacionalização e os desafios dos novos padrões mínimos para a educação em Terapia Ocupacional propostos pela World Federation of Occupational Therapists (WFOT)
}

\author{
Internationalization and the challenges of the World Federation of \\ Occupational Therapists (WFOT) Minimum Standards for the Education \\ of Occupational Therapists
}

\author{
Elisabete Ferreira Mângia*, Marília Meyer Bregalda**
}

Os efeitos e resultados da Declaração de Bolonha, firmada em 1999 pelos ministros da educação de 45 países europeus, convergem para o estabelecimento de padrões e diretrizes comuns que possam dar parâmetros aos processos globais de qualificação e unificação curriculares, dupla diplomação, intercâmbios e cooperação entre universidades, mobilidade internacional estudantil e profissional. $\mathrm{Na}$ atualidade, tal perspectiva se tornou um objetivo global que atinge também o Brasil, que em suas universidades vem implementando políticas de internacionalização. O modelo europeu busca nortear a formulação de padrões formativos mínimos e comuns para todas as profissões e se orienta pela pedagogia das competências ${ }^{1}$.

Os padrões de competência refletem consensos profissionais e sociais. Englobam os conhecimentos, as habilidades, as atitudes, os processos cognitivos, as disposições éticas, sociais, legais e morais, além da postura reflexiva necessária ao desenvolvimento de boas práticas. A expectativa é de que todos os membros de uma profissão compartilhem de um determinado conjunto de competências básicas ao ingressarem na prática profissional e que essa formação básica possa ser permanentemente desenvolvida e aprimorada, ao longo das trajetórias profissionais ${ }^{2}$.

$\mathrm{Na}$ Terapia Ocupacional, o processo vem sendo coordenado por instituições e organizações europeias como o Council of Occupational Therapists for the European Countries (COTEC) e o European Network of Occupational Therapy in Higher Education (ENOTHE) ${ }^{3}$. Busca construir propostas formativas flexíveis e de qualidade, comparáveis entre diversos países e capazes de responderem às necessidades e mudanças globais. Visa ainda o desenvolvimento de parcerias locais e internacionais que promovam e deem visibilidade à Terapia Ocupacional ${ }^{3}$.

Um consenso inicial se articulou em torno da definição de 31 competências consideradas genéricas e comuns a todas as profissões. Define também 34 competências especificas para a Terapia Ocupacional distribuídas em: conhecimentos teóricos específicos; processo e raciocínio profissional; relações profissionais e parcerias; autonomia e responsabilização; pesquisa científica e desenvolvimento da Terapia Ocupacional; gestão e promoção da Terapia Ocupacional ${ }^{3}$.

\footnotetext{
*Editora da Revista de Terapia Ocupacional da Universidade de São Paulo - USP.

** Docente do Curso de Terapia Ocupacional da Universidade Federal da Paraíba - UFPB.
} 
Na mesma direção, do fortalecimento do perfil identitário da profissão e do alinhamento dessas proposições com o paradigma psicossocial e com a pedagogia das competências, a World Federation of Occupational Therapists (WFOT) revisou, em 2016, os Padrões Mínimos para a Educação de Terapeutas Ocupacionais, incorporando à profissão, além do foco da internacionalização dos currículos, padrões propostos por organizações internacionais como a Organização Mundial de Saúde (OMS) e a Organização das Nações Unidas para a Educação, a Ciência e a Cultura - UNESCO ${ }^{4}$. Os padrões mínimos têm como principais contribuições: manter padrões nacionais consistentes; garantir a qualidade da educação profissional; apoiar o crescimento e desenvolvimento de cursos de terapia ocupacional e da profissão; monitorar os padrões educacionais internacionais para identificar tendências; e garantir possibilidades de mobilidade na graduação.

A proposta da WFOT de $2016^{4}$ amplia conteúdos em relação aos padrões publicados em 2002, embora mantenha seus principais aspectos. A expansão se dá em relação a: 1) Defesa dos direitos humanos e construção do senso de justiça social como princípios centrais que orientam a prática profissional;2) Centralidade das habilidades leves que passam a ser consideradas essenciais diante dos desafios do século XXI; 3) Apresentação e descrição, minuciosa e detalhada, dos conhecimentos, habilidades e atitudes que compõem cada uma das cinco áreas de competências propostas no documento; 4) Define o perfil dos terapeutas ocupacionais como agentes de transformação social e de defesa da cidadania e dos direitos humanos.

Norteia a proposta a abordagem centrada no cliente e a concepção ampliada de Ocupação, definida como ferramenta para o desenvolvimento social e comunitário, participação e engajamento, promoção e restauração da saúde, do bem-estar e da cidadania. Defende que os processos em Terapia Ocupacional devem visar sempre a inclusão e participação social e a equidade em saúde.

Os novos padrões então articulados a partir de cinco áreas de conhecimentos, habilidades e atitudes essenciais para a prática dos terapeutas ocupacionais: 1) Relação indivíduo-ambiente-ocupação e sua relação com a saúde, bem-estar e direitos humanos; 2) Relações terapêuticas e profissionais; 3) Processo terapêutico ocupacional; 4) Raciocínio e comportamento profissional; 5) Contexto da prática profissional e 6. Desenvolvimento de práticas baseadas em evidências.

Destaca-se também a orientação de que os programas educacionais sejam organizados a partir de 6 diretrizes; a) Filosofia e propósito; b) Definição de conteúdos no contexto de um desenho curricular singular; c) Definição dos métodos pedagógicos; d) Definição dos cenários de prática; e) Definição sobre as formas de financiamento e f) Definição sobre o perfil dos educadores adequados a cada desenho curricular.

Para o cenário nacional, é importante que a perspectiva colocada tão claramente na atualidade do cenário internacional possa dialogar com as atuais proposições de mudanças das diretrizes curriculares e que os cursos de Terapia Ocupacional possam estar preparados para os novos processos de acreditação internacional, intercâmbios e mobilidade estudantil e profissional.

\section{REFERÊNCIAS}

1. Perrenoud P. Dez novas competências para ensinar: convite à viagem. Trad. Patrícia Chittoni Ramos. Porto Alegre: Artmed; 2000 .

2. Rodger S, Clark M, Banks R, O’Brien M, Martinez K. A comparison of international occupational therapy competencies: implications for Australian standards in the new millennium. Aust Occup Ther J. 2009;56:372-83. doi: 10.1111/j.1440-1630.2009.00808.x.

3. Council of Occupational Therapists for the European Countries - COTEC, European Network of Occupational Therapy Higher Education - ENOTHE. Reference Points for Degree Programmes in Occupational Therapy. Bilbao: Universidad de Bilbao; 2008 [cited 2018 Dec 27 ]. Available from: http://www.unideusto.org/tuningeu/images/stories/Publications/OCCUPATIONAL_THERAPY_FOR_WEBSITE.pdf.

4. World Federation of Occupational Therapists. Minimum standards for the education of occupational therapists. WFOT; 2016 [cited 2018 Dec 27]. Available from: https://www.mailmens.nl/files/21072349/copyrighted+world+federation+of +occupational+therapists + minimum+standards+for+the+education+of+occupational+therapists+2016a.pdf. 